\title{
Direitos humanos e ODS: caminhos para fortalecer os direitos das mulheres
}

\section{- Derechos humanos y ODS: caminos para fortalecer los derechos de las mujeres}
- Human rights and SDGS: pathways to strengthen women's rights

Resumo: O Brasil é um país com uma profunda desigualdade nas relações entre homens e mulheres em vários campos. Em relação ao acesso a terra e territórios há um contexto de profunda concentração fundiária. Ao mesmo tempo, garantir a igualdade de gênero no que tange ao direito à terra se coloca como uma dimensão essencial para uma série de outros direitos humanos. Dessa forma, e considerando que o processo de empoderamento das mulheres é um dos caminhos para reverterem as desigualdades de gênero e promover a luta por direitos, analisar experiências que contribuem neste caminho permite indicar avanços e lacunas, possibilitando sua ampliação. Este estudo tem como objetivo discutir as potencialidades de monitoramento das políticas públicas nos territórios, articuladas aos ODS, a partir de uma experiência local-global, com recorte de gênero, tomando como referência o trabalho com mulheres rurais e urbanas, de movimentos sociais de luta pela terra e moradia, na região nordeste do Brasil desenvolvida pela organização Espaço Feminista. Dita experiência, realizada com base em um modelo que une pesquisa, formação, alianças e incidência política, vem potencializando o processo de autonomia e atuação das mulheres no monitoramento da implementação das políticas públicas e na exigibilidade de seus direitos.

Palavras chave: Direitos humanos, Mulheres. Empoderamento. Políticas públicas, ODS.

1 Pedagoga. Doutora em Direitos Humanos pela Universidade de Salamanca (Espanha). Pesquisadora do Núcleo de Estudos e Pesquisas Educação em Direitos Humanos da Universidade Federal de Pernambuco (Brasil). Consultora da organização Espaço Feminista. E-mail: cftav74@gmail.com 
Resumen: Brasil es un país con una amplia desigualdad en las relaciones entre hombres y mujeres en diversos ámbitos. Respecto al acceso a la tierra y territorios hay un contexto de grande concentración de tierras. A la vez, garantizar la igualdad de género respecto al derecho a la tierra se presenta como una dimensión esencial para un conjunto de otros derechos. De esa forma, y considerando que el proceso de empoderamiento de las mujeres es uno de los caminos para revertir las desigualdades de género y promover la lucha por derechos, analizar experiencias que contribuyen en este camino permite indicar avances y lagunas, posibilitando su ampliación. Esta investigación tiene el objetivo de discutir las potencialidades de monitoreo de las políticas públicas en los territorios, articuladas a los ODS, a partir de una experiencia local-global, con recorte de género, tomando como referencia el trabajo con mujeres rurales y urbanas, de movimientos sociales de lucha por la tierra y la vivienda, en la región nordeste de Brasil desarrollada por la organización Espacio Feminista. Dicha experiencia, realizada con base en un modelo que une investigación, formación, alianzas e incidencia política, viene potenciando el proceso de autonomía y actuación de las mujeres en el monitoreo de la implementación de las políticas públicas y en la exigibilidad de sus derechos.

Palabras clave: Derechos humanos. Mujeres. Empoderamiento. Políticas públicas. ODS.

Abstract: Brazil is a country with a profound inequality in relations between men and women and in diverse fields. Regarding access to land and territories, there is a context of huge land concentration. At the same time, ensuring gender equality with regard to the right to land is an essential dimension for a number of other human rights. Hence, and considering that the process of women's empowerment is one of the ways to reverse gender inequalities and promote the battle for rights, analyzing experiences that contribute to this path allows us to indicate advances and gaps, enabling their adjustment and development. This study aims to discuss the potential for monitoring public policies in the territories, linked to the SDGs, from a local-global experience, with a gender approach, taking as a reference the work with rural and urban women, from social movements fighting for land and housing, in the Northeast region of Brazil that has been developed by the organization Espaço Feminista. This experience, based on a model that interconnects research, political formation, alliances building and advocacy, has been strengthening the process of women's autonomy and the presence of women in monitoring the implementation of public policies and the enforcement of their rights.

Keywords: Human rights. Women. Empowerment. Public policies. SDGs. 


\section{Introdução}

A importância de articular o empoderamento das mulheres, a igualdade de gênero e os direitos humanos reside na necessidade de enfrentar e modificar a situação de desigualdade de gênero e de resgatar a relação entre vida cotidiana e democracia a fim de possibilitar, entre outros aspectos, a construção de uma cultura de direitos.

No Brasil, apesar de recentes avanços nas legislações e alguns esforços até o ano de $2016^{2}$ em planejamento e políticas, ainda contamos com uma profunda desigualdade nas relações entre homens e mulheres em vários campos, entre eles o acesso à terra e territórios.

Em relação a esta última questão, por exemplo, o país vive um contexto de profunda concentração fundiária, que remonta a uma longa história de terras concentradas nas mãos de uma elite masculina e branca. O Brasil tem mais de 850 milhões de hectares, dos quais 351 milhões de hectares são estabelecimentos agropecuários, ou seja, áreas agricultáveis que correspondem quase a metade do território brasileiro, e também tem mais de 117 milhões de hectares em terras indígenas e quase 152 milhões de hectares em unidades de conservação. O Censo Agropecuário aponta que a concentração fundiária no país é muito grande, no total quase 4,5 milhões de estabelecimentos ocupam quase 72 milhões de hectares, enquanto pouco mais de 470 mil estabelecimentos ocupam quase 280 milhões de hectares. O resultado disso é a disputa por terra, é o empobrecimento do campo, é falta de alimento; e o Estado brasileiro não vem se mostrando capaz de inverter este quadro e propiciar uma distribuição de terras de forma equitativa.

Sob a perspectiva de gênero chama atenção o escasso número de beneficiárias da posse segura da terra e da moradia em comparação com outros países latino-americanos (DEERE; LEÓN, 2003). Apesar de que a Constituição Federal de 1988, no seu artigo 189, estabelece que o título de domínio e a concessão de uso serão conferidos ao homem ou à mulher, ou a ambos, independentemente do estado civil.

No ambiente rural as mulheres exercem papel essencial na produção e na preservação dos recursos naturais, atuando como protagonistas nas atividades agroecológicas. Contudo, apesar de participarem ativamente da produção, o igual acesso à terra não tem sido garantido para as mulheres (BUTTO; HORAS; DANTAS, 2014).

Esse cenário de desigualdade no direito à terra se deve, entre outros

2 Ano da ruptura democrática no país, com o golpe jurídico-parlamentar, empresarial e midiático que retirou do poder a presidenta eleita. As eleições de 2018 e o atual governo confirmam essa tendência de ruptura e desprezo pelas instituições democráticas e o Estado de Direito. 
aspectos, a uma preferência masculina na herança, ao privilégio masculino no casamento, ao viés de gênero em programas de distribuição de terras e no mercado fundiário, que, combinado com as distorções no mercado de trabaIho e de crédito, leva as mulheres a terem menos acesso à terra comparado aos homens (DEERE; LEÓN, 2003).

Por outro lado, estudos realizados em vários países, organizados pela ILC (International Land Coalition) mostram que as mulheres com direitos à terra assegurados possuem rendimentos até 3,8 vezes maiores e estão 8 vezes menos propensas a sofrer violência doméstica. Nesse sentido, a posse segura da terra pelas mulheres está profundamente associada com seu bem-estar e seu empoderamento e autonomia. Também há uma série de estudos na América Latina que mostram que as mulheres proprietárias da terra têm mais condições de escolha em relação aos parceiros no casamento, e dentro dele desempenham um papel muito maior, tanto na tomada de decisões referentes à casa e à propriedade, como às decisões sobre a produção e os usos dos recursos econômicos (DEERE; LEÓN, 2003).

Diante desse contexto, e considerando que a igualdade de gênero e o empoderamento das mulheres são marcos fundamentais para transformá-lo, a organização brasileira Espaço Feminista, cuja missão é o processo de empoderamento de mulheres rurais e urbanas no Estado de Pernambuco, desenvolve um trabalho com base em um modelo que integra quatro eixos: a produção do conhecimento; a formação política e técnica; a criação de alianças; e a incidência política, que inclui diálogo local com o poder público e monitoramento das políticas públicas nos territórios; este último articulado aos Objetivos de Desenvolvimento Sustentável (ODS) ${ }^{3}$ 1, 2, 5 e 11, com a finalidade de fortalecer os direitos das mulheres à terra. No modelo criado pelo Espaço Feminista o processo de empoderamento articula três níveis da vida das mulheres participantes: o nível individual; o nível das relações dentro dos seus espaços de luta nos seus movimentos de origem; e o nível de influência nas políticas públicas. E cada um de seus eixos está orientado pela perspectiva de gênero, considerando que esta "tem como um de seus fins contribuir à construção subjetiva e social de uma nova configuração a partir da ressignificação da história, sociedade, cultura e política desde as mulheres e com as mulheres" (LAGARDE, 1996, p.13).

Com este tipo de atuação a organização busca gerar espaços diversos

3 Em 2015 a ONU aprovou a Agenda 2030, composta por 17 ODS e 169 metas, entre as quais a igualdade de gênero (ONU, 2015). Apesar das críticas e dos interesses geopolíticos em questão, não se pode desconsiderar o cenário de correlação de forças e disputa de direitos que se estabelece em face ao multilateralismo de organismos como a ONU, cujo sistema internacional de proteção dos direitos humanos tem adesão da maior parte dos países do mundo e é acionado pelos movimentos sociais. 
para pensar, explicar e dar voz própria as mulheres, criando discursos e práticas que sejam capazes de desvelar a assimetria real dos espaços de poder e do acesso aos direitos, a fim de se contrapor aos contextos naturalizados, que omitem a construção social das desigualdades, abrindo espaços de compreensão, ressignificação e transformação. A aposta é por mostrar as barreiras materiais que impedem o acesso e a vivência dos direitos, por desarticular os modos - localizados e situados - da exclusão, por explicar como as fraturas do campo social se potencializam na opressão de gênero e como a subordinação de gênero potencializa a exclusão (FEMENÍAS, 2007).

Experiências como esta que se desenvolvem para contribuir ao empoderamento das mulheres em articulação com os direitos humanos, como um dos caminhos para reverter as desigualdades de gênero, constituem um importante elemento de análise pelo qual se pode indicar avanços e dificuldades e contribuir para repensar algumas práticas a fim de colaborar com sua ampliação.

Assim, este estudo tem como objetivo discutir as potencialidades de monitoramento das políticas públicas nos territórios, articuladas aos ODS, a partir de uma experiência local-global, com recorte de gênero, tomando como referência o trabalho com mulheres rurais e urbanas, de movimentos sociais de luta pela terra e moradia, na região nordeste do Brasil desenvolvida pela organização Espaço Feminista. Para isso, a opção metodológica é a abordagem qualitativa (GHEDIN; FRANCO, 2008; GIL, 1994), com estudo de caso e observação não participante das atividades, utilizando a análise de conteúdo (BARDIN, 1977) para os relatos das mulheres participantes, e para os diversos documentos referentes ao tema, como relatórios, dados de pesquisa realizada pela organização, diretrizes teórico-metodológicas, entre outros ${ }^{4}$, e centrando-se no diferencial do processo, como também em suas evidências a partir da relação entre os eixos de atuação e seus desdobramentos.

O foco no monitoramento se justifica por apresentar-se como meio para incidir nas políticas públicas de maneira articulada e consistente, apontando à necessidade do conhecimento coletivo de cada contexto e do exercício do controle social por parte das mulheres para que a exigibilidade de seus direitos se converta em prática cotidiana.

Aqui é importante assinalar que incidir e monitorar as políticas públicas nos territórios com base nos dados de pesquisa primária e articular este trabalho a uma agenda global não significa que a organização compartilhe integralmente de suas premissas. Ao contrário, o Espaço Feminista insere a discussão sobre os ODS desde uma perspectiva crítica, usando os indicadores para aplicar na realidade local e demonstrar que apesar de todos os recursos 
e os esforços dos governos e das agências internacionais estarem dirigidos para a Agenda 2030 qualquer processo de mudança vai se dar a partir da resistência e da organização nos territórios, a partir da capacidade que as muIheres e os grupos têm de dialogar com seus governos locais e exercer influência sobre a pauta e as políticas a nível local.

Por fim, o presente texto está organizado em três partes mais as considerações finais. Na primeira é apresentada a metodologia de trabalho, na segunda são discutidos os conceitos de gênero, empoderamento e direitos humanos que orientam a experiência, e na terceira são abordados os pontos principais, relacionados aos direitos humanos, políticas públicas, ODS e empoderamento das mulheres.

\section{A metodologia e os eixos do modelo}

O processo de empoderamento, que vem sendo desenvolvido com mulheres rurais e urbanas em Pernambuco, foi iniciado em 2008 e foi sendo construído a partir de metodologia própria, que é constantemente revisitada em um processo de reflexão-ação-reflexão (FREIRE, 1997), com base nas lentes de gênero (CASTAÑEDA, 2008).

O modelo começou a ser aplicado em 2010 no processo de regularização fundiária em 'Ponte do Maduro', região urbana do Recife formada por quatro comunidades com um total de 8.000 famílias, que garantiu uma governança de terra sensível à gênero, com os títulos de posse da terra em nome das muIheres. A atuação em 'Ponte do Maduro' ofereceu uma contribuição valiosa no sentido de compreender a forma pela qual a desigualdade de gênero se reproduz nas instituições e como afeta a equidade de gênero na implementação das políticas públicas. Também permitiu analisar as diversas formas de reprodução de uma cultura machista e patriarcal que inferioriza a participação das mulheres, especialmente nos processos de tomada de decisão.

A ação continuada ao longo dos anos em 'Ponte do Maduro' permitiu perceber como elementos do modelo de empoderamento foram sendo incluídos, integrados e aprofundados de maneira a possibilitar sua revisão e a aperfeiçoa-lo. A partir de 2017, com o modelo constituído por quatro eixos, este trabalho foi ampliado para o interior do Estado5.

Nesta direção, a metodologia de trabalho empregada decorre das diretrizes e estratégias da organização, e considera o contexto de trabalho, o enfoque metodológico específico e a circularidade do modelo. Em relação

5 Foi neste momento que o eixo relacionado ao monitoramento foi articulado aos ODS como um dos caminhos para desconstruir as propostas globais desconectadas das realidades locais e das necessidades das mulheres. 
às diretrizes de trabalho a organização atua na perspectiva de processo; não executa o que é papel do Estado; reconhece a existência de diferentes conhecimentos; estimula a dialogicidade, a autonomia e a criatividade; e atua para a exigibilidade das políticas e direitos. Em conexão com estas, tem como estratégias integrando seu referencial metodológico: respeitar o protagonismo das mulheres como sujeitos políticos; promover a afirmação das relações democráticas entre os grupos e nos espaços de atuação; proporcionar a articulação entre os conhecimentos e o cotidiano das práticas sociais das mulheres; estimular a interlocução com o poder público; e atuar no nível comunitário de forma a influenciar as políticas públicas nas três esferas - municipal, estadual e federal.

Ademais, deve-se considerar o contexto de trabalho e o enfoque metodológico específico. Em relação ao primeiro, é preciso ter em conta que a atuação ocorre no espaço rural e urbano de forma integrada e enquanto territórios articulados, com mulheres lideranças e participantes de movimentos de luta pela terra e pela moradia que transitam ao mesmo tempo nos dois espaços, a fim de fortalecer seus vínculos a partir da compreensão dos problemas comuns e da necessidade da atuação conjunta e solidária. Quanto ao segundo, o enfoque metodológico se fundamenta na pedagogia feminista, na educação em direitos humanos e na educação popular freiriana. Isto porque estas favorecem a percepção da realidade, sua análise, uma postura crítica frente a ela e a participação dialógica e democrática.

Em relação à circularidade do modelo, cabe apontar a característica de articulação e retroalimentação entre seus eixos que indica que o trabalho se constitui em um processo, e não em uma atuação com etapas estanques, que não se comunicam nem se influenciam. Isso se traduz na existência de movimentos diferenciados de compreensão e efetivação das ações em relação aos tempos, espaços, condições locais e apreensões dos conteúdos.

Como também se assinala a importância de cada um dos eixos e deles conjuntamente. Na produção do conhecimento articula-se a produção de um diagnóstico local e da região, que possa, por um lado, contribuir ao processo de tomada de consciência de sua realidade por parte das mulheres, e, por outro lado, influenciar as políticas públicas. Movimento que é aperfeiçoado ao situar as mulheres como protagonistas da ação de pesquisa.

O processo formativo, que ocorre de forma permanente, busca aliar a análise crítica da realidade à construção da autonomia pessoal e sociopolítica das mulheres, tendo como objetivo "incorporar estratégias e critérios para a formação de ideias e subjetividades críticas e emancipatórias" (TORRES, 2013, p. 27). Neste sentido, destaca-se a importância da pedagogia feminista como "uma pedagogia entre mulheres onde cada uma possa ensinar a outra e ao mesmo tempo aprender com a outra". Esta prática tem dois fundamentos: 0 
primeiro "consiste em reconhecer os saberes das mulheres e os saberes específicos de cada uma", o outro "consiste em conceder autoridade às mulheres por sua sabedoria intelectual, seus conhecimentos, suas habilidades e suas descobertas" (LAGARDE, 2000, p. 26). Especialmente porque "o desafio não é apenas pedagógico, é criar relações políticas entre sujeitos que sejam capazes de agir coletivamente por transformações que interessem aos diversos segmentos de mulheres" (SILVA, 2010, p. 20-21).

Com a criação de alianças, parcerias e divulgação do trabalho, ampliam-se o campo de ação e a capacidade de pensar coletivamente as políticas públicas pelas particularidades e fortalezas da atuação em rede.

O trabalho de incidência política, por meio de diálogo local e monitoramento, é por excelência o espaço de influenciar a formulação de políticas públicas. Neste sentido, o monitoramento se alimenta das pesquisas, mas também produz conhecimento; necessita da formação técnica e política, ao mesmo tempo em que se constitui em processo formativo; contribui para dar visibilidade às questões locais, mas também amplia seu leque de inserção local-global.

A ideia no desenvolvimento do trabalho, portanto, é oportunizar a mudança na vida das mulheres através da participação delas na formulação, implementação e monitoramento das políticas públicas. Como também de contribuir na melhora de sua posição em diferentes níveis a partir do estabelecimento de uma nova relação com o poder público a fim de que a política de regularização fundiária em seus territórios se realize com base em critérios de equidade de gênero, estabelecendo as condições para que haja uma governança de terra sensível a gênero.

Essas escolhas se alinham às novas formas de construção e de poder, considerando que "atualmente, o pensamento crítico encontra desafios complexos", o que implica dizer que "além de pensar nos contextos e nas categorias relacionadas com políticas públicas, se espera dele que produza, a partir do diálogo com os movimentos sociais, contribuições a objetivos concretos e propostas sobre como alcança-los" (CAROSIO, 2017, p. 23).

Todas as fases do processo, incluído o monitoramento da implementação das políticas, estão permeadas por um marco teórico pertinente ao trabalho que é apresentado a seguir.

\section{Gênero, empoderamento e direitos humanos}

As questões de gênero, direitos humanos e empoderamento das muIheres são as que adquirem maior notabilidade na atualidade e que, por seu potencial, são fundamentais ao processo de construção da autonomia e atuação das mulheres na exigibilidade de políticas públicas que possibilitem ga- 
rantir seus direitos. Neste contexto, os direitos humanos são compreendidos como os "processos institucionais e sociais que possibilitem a abertura e consolidação de espaços de luta pela dignidade" (HERRERA FLORES, 2008, p. 13). Gênero, por sua vez, é um conceito construído socialmente, que possibilita compreender as relações estabelecidas entre os homens e as mulheres, a partir das diferenças apreendidas entre os sexos e as relações de poder estabelecidas entre eles. Nesta perspectiva, gênero deve ser visto como elemento constitutivo das relações sociais e um modo de significar relações de poder (SCOTT, 1990).

Assim é essencial a compreensão da relação entre gênero e poder. Por isso mesmo, deve considerar-se que "a associação de determinadas características a cada sexo não é resultado do azar, mas da utilidade que nele encontram as sociedades e que historicamente conduziu ao estabelecimento e posterior consolidação da referida posição dominante dos homens na sociedade" (MANZANO, 2006, p. 47).

Por não se constituir num processo linear, o empoderamento é compreendido como "um processo complexo, multidimensional, pessoal, não imposto e participativo, que se produz através da experiência" (MÉNDEZ, 2006, p. 93). No campo das relações de gênero, o empoderamento significa "sair do controle, da submissão, da subordinação e da opressão" (MÉNDEZ, 2006, p. 90) dessas relações.

A partir dessa perspectiva de inversão das relações desiguais de poder, este último perde sua concepção tradicional de "poder sobre", para converter-se numa concepção de "poder para" e "poder com". Nessa nova concepção o empoderamento "busca facilitar um processo multidimensional e interconectado de transformação das relações sociais de poder que proporcione às mulheres ter o controle sobre suas vidas" (MANZANO, 2006, p. 37).

Neste sentido, o processo de empoderamento articulado ao exercício do controle social aparece como um dos caminhos para alcançar a democracia de cidadania (PNUD, 2004). Uma democracia que permita a construção de uma cultura de direitos, garantindo o respeito à diversidade e à diferença e que se apoie em condições crescentes de igualdade.

Por isso "o processo de desafiar as relações de poder existentes, assim como o de obter um maior controle sobre as fontes de poder, podem ser chamados empoderamento" (BATLIWALA, 1997, p. 193).

E por que o empoderamento das mulheres é necessário? Porque,

A característica mais destacada do termo empoderamento é que contêm a palavra poder, a qual pode ser amplamente definida como o controle sobre os bens materiais, os recursos intelectuais e a ideologia. O poder, portanto, se acumula para aqueles que controlam ou estão capacitados para influir na distribuição dos recursos materiais, o conhecimento e a ideologia que governa as relações sociais, tanto na vida privada como na pública. Este controle, por sua vez, 
confere o poder de decisão. (...) Por isso o empoderamento se manifesta como uma redistribuição do poder. As metas do empoderamento das mulheres são desafiar a ideologia patriarcal (dominação masculina e subordinação da mulher), transformar as estruturas e instituições que reforçam e perpetuam a discriminação de gênero e a desigualdade social e capacitar as mulheres para lograr acesso e controle da informação e dos recursos materiais (BATLIWALA, 1997, p. 191-194).

Compreender estas questões é o primeiro passo para avançar em um trabalho coletivo, que possibilite articular direitos humanos e políticas públicas locais, relacionadas aos $\mathrm{ODS}^{6}$, no processo de empoderamento das muIheres com a finalidade de contribuir para transformar suas realidades.

\section{Direitos humanos, políticas públicas, ODS e o empode- ramento das mulheres}

O olhar para as potencialidades de monitoramento das políticas públicas nos territórios, com base na experiência analisada, demanda inicialmente a abordagem sobre o eixo da produção do conhecimento, que é o que orienta o trabalho de incidência política, onde está inserido o monitoramento.

$\mathrm{Na}$ atual experiência em Pernambuco a atuação foi iniciada na região da Mata Norte e já vem ocorrendo há quatro anos na região Agreste, de forma mais específica em dois territórios - Bonito e Caruaru, escolha realizada com base nos seguintes critérios: área, população, IDH, PIB e apoio dos movimentos sociais e do governo local. Aqui cabe ressaltar que o trabalho na região Agreste é realizado em uma situação mais complexa que em Ponte do Maduro, pela multiplicidade de políticas a serem monitoradas, associado ao fato de a atuação ser feita em mais de um município e em diversas comunidades.

Nesses territórios o eixo da produção do conhecimento foi realizado por meio de: a) visitas de reconhecimento do território e dos grupos, de modo a respeitar a realidade local; b) análise dos planos diretores e levantamento dos dados populacionais dos dois municípios, entre os quais o tamanho da população de proporção urbana e rural, sua distribuição física e conformação; c) levantamento de dados secundários oficiais junto a órgãos públicos, como por exemplo na base de dados do Instituto Brasileiro de Geografia e Estatística (IBGE) - Censo Demográfico e Censo Agropecuário - com o objetivo de saber

6 Conforme dito antes a articulação com os ODS é aplicada de maneira a questionar a lógica de uma agenda global que não considera os contextos locais e a diversidade das mulheres e seus direitos, utilizando a incidência e monitoramento das políticas e pautando a agenda pública local. Essa experiência tem sido discutida desde 2018 em espaços internacionais e nacionais; em órgãos públicos e com os movimentos sociais. O que tem possibilitado a avaliação da experiência e a definição de estratégias para influenciar a ação do local para o global. 
o que precisava ser aprofundado e verificado com a pesquisa de campo; d) aplicação de 469 questionários (com o tamanho da amostra definida segundo os padrões científicos) nos dois municípios para conhecer a realidade local e obter dados sobre a percepção da posse da terra; a documentação da propriedade; e sobre seu uso e controle; e) realização de seis grupos de discussão, que reuniu em torno a 70 mulheres que já haviam participado da pesquisa quantitativa.

Seguindo a metodologia feminista (CASTAÑEDA, 2008) houve a definição de que as aplicadoras dos questionários fossem mulheres dos territórios pesquisados com atuação em causas relativas à terra. Além disso, a composição de uma equipe multidisciplinar e o estabelecimento de parcerias institucionais governamentais e não governamentais e de redes sociais atuantes em cada local foi outro ponto importante para a efetivação do trabalho. Finalizado a atividade de campo, os questionários foram organizados, tabulados e seus resultados analisados. Também foram realizadas reuniões com as entrevistadoras para refletir sobre sua experiência de participação no estudo e sobre questões gerais que emergiram no campo de pesquisa.

Nesta direção, conhecer para compreender os territórios e os sujeitos que ali estabelecem suas vidas é o ponto de partida para a produção de conhecimento de maneira inclusiva. Os dados relativos aos territórios foram obtidos a partir da análise dos dados secundários, e as informações sobre os sujeitos são reveladas por meio do perfil das participantes da pesquisa quantitativa.

Caruaru é um município com população de 356.128 mil habitantes, enquanto em Bonito residem 38.044 mil pessoas, segundo o IBGE. A população caruaruense, portanto, é cerca de nove vezes maior do que a do município vizinho. Em ambos a população se concentra na área urbana. Ao mesmo tempo, Caruaru possui o maior Produto Interno Bruto (PIB) entre os municípios localizados no interior do Estado. Bonito possui o quinto PIB entre os municípios do Agreste Central. Contudo, o seu valor é, aproximadamente, dezenove vezes menor, quando comparado com o de Caruaru. Além disso, a economia de Caruaru é dinâmica, apresentando-se como um ponto nodal na região e concentrando uma diversidade de atividades, e integrando o Polo de Confecções do Agreste, o segundo maior polo têxtil do país. Bonito, por outro lado, tem sua economia centrada no setor agropecuário. E enquanto em Bonito a água não é um problema, por fazer parte de duas importantes bacias hidrográficas, a população residente na zona rural de Caruaru enfrenta dificuldades para se reproduzir socialmente através da agricultura em função da escassez de água no município.

Compondo o perfil das mulheres participantes do estudo temos informações sobre a faixa etária, a escolaridade, a cor/raça autodeclarada, a ocupação, o estado civil e situação conjugal, e a chefia de família. O perfil 
das participantes é o de mulheres adultas, autodeclaradas pardas ou brancas, agricultoras, com baixa escolaridade, solteiras/morando junto, com filhos/as e em muitos casos chefiando a família. Estas mulheres no município de Bonito vivem na zona urbana, mas são agricultoras e toda sua referência é do ambiente rural. Já no município de Caruaru as mulheres na zona rural acabam tendo que se dedicar a atividades urbanas, como o fabrico, tendo, portanto, mais referência do ambiente urbano.

Cabe ainda um ponto a destacar: do universo das mulheres que indicaram ser solteiras: a maior parte declarou que vive em união estável. Estes dados - de estar solteira e morar junto - revelam algo essencial para analisar a desigualdade de gênero em face da questão fundiária, especialmente porque são indicativos de uma grande insegurança jurídica em relação à posse da terra em caso de separação ou de falecimento do companheiro. Neste sentido, a compreensão da conjuntura familiar é elemento primordial na análise da segurança da posse tanto para as mulheres participantes deste estudo, quanto para todas as mulheres que se encontram na mesma situação.

Correspondendo ao contexto sócio histórico brasileiro fundamentado na desigualdade de gênero, nos momentos da aplicação dos questionários e também durante os grupos de discussão foi possível perceber o machismo presente e permeando as relações sociais e conjugais bem como a maneira como esse fator tem impacto no acesso à terra por parte das mulheres.

A ausência de oficialização da união entre os casais pode ter motivações distintas, mas duas delas (de forma isolada ou articulada) podem explicar a razão da existência de um número mais reduzido de mulheres casadas no civil: por um lado, a falta de condições financeiras para realizar o casamento civil, e, por outro, a cultura patriarcal, que estimula a preferência dos homens a permanecer solteiros para não ter que dividir os bens com a esposa, e assim assegurar seus direitos em caso de separação ou herança.

Ao mesmo tempo, as questões centrais da pesquisa se situam nos aspectos relacionados à terra: propriedade ou posse, tipo de posse, segurança da posse e fatores de risco, entre outros. A importância de ter um diagnóstico sobre a situação local em relação a estas questões decorre do fato de a propriedade ou posse da terra constituir-se como um indicador fundamental no campo da autonomia, do poder e do empoderamento econômico das muIheres (DEERE, 2011). Especialmente por representar um dos caminhos para transformar a realidade das mulheres quanto a relações de subordinação, dependência econômica e violência.

Os principais resultados da investigação foram: a) mais da metade das mulheres entrevistadas (56\%) afirmou ter a posse ou propriedade da terra; $b$ ) a maior parte das entrevistadas $(52,6 \%)$ afirmou possuir algum documento da 
propriedade da terra; mas quando questionadas sobre o tipo de documento, indicaram: título de propriedade $(19,8 \%)$, promessa de compra e venda $(14,4 \%)$ e cessão de direito hereditário $(3,9 \%)$; c) a situação das participantes em relação à terra foi colocada em termos de ser proprietária $(36,7 \%)$, herdeira $(28,4 \%)$, e de pagar para usar a terra $(13,2 \%)$; o que indica a forma como se adquire a terra: compra, herança ou aluguel; d) ao ser questionadas se o uso da terra ultrapassa a função de moradia, agregando seu uso para o trabalho, parte delas (44,3\%) disse que sim; e) com base na percepção das mulheres, um percentual significativo delas $(75,6 \%)$ afirmou se sentir segura quanto à propriedade da terra; o que indica um distanciamento entre sua percepção e a realidade, considerando que a minoria delas tem título de propriedade.

Diante dos dados apresentados é possível destacar alguns pontos que são relevantes para a compreensão da problemática existente nos territórios no que se refere à questão fundiária com recorte de gênero. $O$ primeiro ponto é a forma de acesso à terra, que na maior parte dos casos ocorre por herança - característica encontrada no rural - e em outros casos ocorre pela compra - característica encontrada no urbano. Aqui é necessário pontuar que apesar de a maior parte das mulheres, no rural, ter indicado a obtenção das terras por herança e a maior parte das mulheres, no urbano, tenha afirmado que obtive a terra por meio da compra, ambos casos, na sua maior parte, se referem à terra sobre as quais estas mulheres não têm a documentação necessária para comprovar a posse. O que indica a necessidade de uma política fundiária que inclua as mulheres, utilizando um marco legal que reconheça seu direito independente de sua situação conjugal e da documentação sobre a herança ou sobre a compra. Especialmente porque essa situação de vulnerabilidade das mulheres em relação à posse segura da terra tem sido utilizada pelos políticos locais como forma de se manter no poder por meio de promessas de regularização fundiária que não são cumpridas. O segundo ponto é o uso que se faz da terra, que de forma geral, ultrapassa a função exclusiva de moradia e passa a representar fonte de sustento, gerando recursos econômicos para a sobrevivência. A terra, portanto, é usada para agricultura, seja para consumo próprio seja para a comercialização. O que novamente demonstra a importância da posse segura da terra, em particular para as mulheres. $O$ terceiro ponto é a segurança expressada nas respostas sobre a posse da terra. Ou seja, a percepção/sentimento das entrevistadas é de estar segura quanto à posse, mesmo que não haja uma relação jurídica que fundamente essa percepção. O que também aponta para a necessidade de instrumentos de regularização para garantir a efetiva segurança da posse.

O conjunto dos dados revelados pelo estudo de corte quantitativo, aqui trazido de forma resumida, não esgotam o potencial do conhecimento 
produzido com/para/pelas mulheres. Muitas questões foram aprofundadas na etapa qualitativa, com os grupos de discussão, e estão fundamentando o processo de monitoramento

Enlace entre a pesquisa quantitativa e o plano de monitoramento, os grupos de discussão (GDs) apresentaram uma tripla função: a) aprofundar as questões que surgiram com os dados oficiais e dos questionários; b) promover a reflexão e o diálogo entre as mulheres sobre questões definidas por elas como importantes, colaborando com seu processo formativo; c) contribuir na construção dos planos de monitoramento das políticas locais, a partir da identificação de problemas e da definição das necessidades e prioridades das mulheres.

A organização dos grupos foi iniciada com a definição das temáticas a serem discutidas que foram indicadas pelas mulheres dos dois municípios. Foram escolhidas as seguintes: I) Direitos da mulher à terra e a percepção da segurança da posse; II) Saneamento básico e meio ambiente; III) Educação para a cidadania e identidade rural; IV) Moradia; V) Água e mudanças climáticas; VI) Violência doméstica. A perspectiva metodológica dos GDs seguiu o caminho dos debates horizontais, constituindo-se em espaços de primazia da fala das mulheres.

Com os GDs foi possível aprofundar uma realidade já indicada na investigação quantitativa, em especial no tocante à concentração da terra e a falta de acesso a bens básicos, comprovando assim as dificuldades cotidianas vivenciadas pelas mulheres, que são geradas pela inadequação das moradias, falta de segurança da posse da terra, falta de saneamento, machismo, etc. Além disso, a participação das mulheres rurais e urbanas dos dois municípios nos mesmos grupos trouxe novos elementos em função do intercâmbio sobre os problemas referentes às suas realidades, reafirmando a estratégia de unir ambos contextos, rural e urbano, para uma atuação conjunta.

Além disso, o fato de serem mulheres que participaram do processo desde seu início, como entrevistadoras e entrevistadas na etapa de investigação, e como participantes nos grupos de discussão potencializa seu processo de empoderamento.

O que conduz a uma situação, gerada pelo saber, em que as mulheres passam a refletir sobre seu contexto e a entender que vivenciam uma realidade comum a todas elas, oportunizando uma ampliação de suas consciências críticas sobre questões que elas próprias antes não compreendiam ou reconheciam e que pode ser percebida em alguns relatos trazidos nas discussões em grupo:

O direito da mulher tem que ser titularizado, cumprido. Temos direito na Constituição, mas não é garantido. Por isso a gente tá procurando assegurar nosso direito (Participante A).

Participar desse processo tem sido importante pra ampliar minha visão. Esse espaço empodera, nós não somos maria vai com as outras. Hoje eu 
posso discutir com a gestão e dizer como é que me sinto segura. Hoje eu consigo chegar no conselho e dizer porque eu preciso dessa moradia (Participante B).

A mulher está mais segura se tem a terra. Quando a terra está no nome da mulher avança mais (Participante $\mathrm{C}$ ).

Por sua vez, o trabalho de incidência política combina a atuação local das mulheres por meio de três grandes blocos: 1 ) incidência em políticas definidas pelos dados da pesquisa de campo e priorizadas pelas mulheres nos territórios, que inclui diálogo com o poder público, monitoramento das políticas a fim de influenciar a agenda pública e a participação na regularização fundiária; 2) ação em rede das mulheres de distintos movimentos nos espaços locais, nacionais e internacionais, como consequência do processo de empoderamento e autonomia das lideranças em suas comunidades; 3 ) ampliação da presença das mulheres nos espaços de formulação das políticas e controle social.

Em relação ao monitoramento das políticas públicas, este engloba um conjunto de atividades dirigidas ao controle social com o objetivo de verificar a implementação das políticas locais associadas às metas vinculadas nos objetivos 1, 2, 5 e 11 dos ODS.

Para isso foi construído de forma coletiva um plano de monitoramento a partir da realidade revelada nos resultados dos grupos de discussão, dos dados quantitativos e dos dados secundários, como também consideradas as prioridades das mulheres participantes. De posse do plano, foram organizados grupos de monitoramento divididos por temáticas em cada município e orientados ao seguimento das políticas e à articulação e interação entre ditos os grupos e os/as gestores/as locais. Cabe pontuar que este trabalho vem sendo realizado pelo grupo de mulheres que atuaram nas etapas anteriores a fim de possibilitar a continuidade de seu processo formativo.

Ademais, são realizados encontros mensais com as mulheres para sua formação técnico-política sobre os conteúdos que integram o plano de monitoramento, a fim de fundamentar o trabalho e estabelecer um espaço de seguimento, troca de experiência e reflexão. Também são realizadas visitas e interlocução com os órgãos relacionados às políticas monitoradas: segurança da posse da terra e regularização fundiária; condições de moradia e habitabilidade; saneamento; sustentabilidade hídrica e acesso à água; soberania alimentar; empoderamento político e comunitário; empoderamento e autonomia econômica.

As monitoras, responsáveis por esta ação, são o elo entre o conjunto de mulheres e a gestão pública e seu trabalho se vê reforçado na organização em rede. Por isso a importância de um processo coletivo, que possibilite aprender umas acerca das outras como pessoas que resistem à colonialidade de gênero; entendida como a opressão racializada e capitalista (LUGONES, 
2011). Assim, o movimento consegue reter modos criativos de pensar, de se conduzir, de se relacionar, que são contrárias à lógica do capital (LUGONES, 2011) e às violações de direitos.

Ao mesmo tempo, a análise crítica sobre os indicadores dos ODS 1, 2, 5 e 11 e as demandas locais indicadas nos planos de monitoramento tem agregado potencial à ação de monitorar a implementação das políticas públicas, contribuindo ao entendimento de que sem uma ação local, metas e objetivos maiores são incapazes de serem atingidos. Isso significa dizer que a prioridade é a de olhar as políticas no nível local, em um processo construído coletivamente, com o protagonismo das mulheres e com base em suas experiências e problemas. O que se justifica por ser no município o espaço onde as políticas públicas, que asseguram direitos, se desenvolvem em sua integralidade, $\mathrm{e}$ também onde a interlocução com o poder público para a exigibilidade dessas políticas ocorre de maneira mais direta. A partir desse âmbito a organização em rede por parte das mulheres na defesa da exigibilidade de seus direitos tem o potencial para expandir esta ação para as demais esferas. Nesta perspectiva, o fluxo ocorre em sentido contrário, ou seja, da base para o topo, mas mantendo a articulação local-global.

Para que este conjunto de ações consiga contribuir às mudanças nas estruturas sociais, econômicas e patriarcais, o trabalho tem sido orientado pela ideia

\begin{abstract}
[...] de que o empoderamento deve gerar uma nova noção de poder. As noções atuais de poder foram desenvolvidas em sociedades hierárquicas de dominação masculina, com base nos valores discriminatórios, destrutivos e opressores. A ideia não é que as mulheres adquiram poder para utilizá-lo de modo igualmente explorador e corrupto. Ao contrário, o processo de empoderamento das mulheres tem que desenvolver uma nova concepção do poder, que assuma formas de democracia e poder compartilhado: a construção de novos mecanismos de responsabilidade coletiva, de tomada de decisões e de responsabilidades (BATLIWALA, 1997, p. 202).
\end{abstract}

Como resultado direto desse trabalho, enquanto processo de empoderamento transformando-se em prática coletiva, as mulheres apresentaram como demanda prioritária a necessidade da regularização fundiária nos municípios onde residem, com ações que incluíssem sua participação; demanda esta que já havia sido apontada na pesquisa e que vem sendo desenvolvida de forma articulada ao monitoramento das políticas.

De acordo com a análise fundiária realizada a partir dessa decisão coletiva foram identificadas diversas áreas nos dois municípios que apresentam condições de ocupação de terra para fins de moradia. Com base nisto foi elaborado um plano de intervenção, fundamentado na Lei Federal ${ }^{\circ}$ 13.465/17 e no Decreto Federal $n^{\circ} 9.310 / 18$. Para cada área, reconhecida como núcleo urbano informal (NUI) foi apresentado à prefeitura correspondente o instrumento espe- 
cífico para este trâmite, chamado REURB-S, que é uma modalidade aplicável aos núcleos informais ocupados por população de baixa renda, que por sua condição tem direito à gratuidade em todos os gastos com a regularização fundiária. Esses núcleos são áreas urbanas de ocupação consolidada e estão em terrenos públicos, caracterizados como áreas de interesse social.

Após esses passos, alguns encaminhamentos foram adotados nos dois municípios no sentido de reunir as condições para a regularização. Em Caruaru ainda não houve posicionamento oficial do poder público à solicitação de REURB-S7 .

Em Bonito o procedimento de REURB-S foi admitido pelo município e em agosto de 2019 a prefeitura fez o lançamento do programa governamental para realizar a regularização fundiária de 17 assentamentos informais, o Programa "Minha Casa é Legal", formalizando-o com a assinatura do Decreto Municipal no 35/2019, além de ter assumido o compromisso de que os títulos de posse da terra sejam colocados em nome das mulheres. Durante o lançamento foi anunciada parceria entre a prefeitura e o Espaço Feminista para o apoio a esta ação a fim de garantir uma governança de terra sensível a gênero. Foi então criada uma comissão local, responsável pela regularização, tendo entre seus participantes três monitoras. O que demonstra a relação entre o processo de monitoramento que vem sendo desenvolvido, o trabalho da comissão e a implementação dessa política. Na ocasião também foi criada uma equipe técnica para assessorar o município neste processo, composta por integrantes do Espaço Feminista das áreas de regularização fundiária, geografia e arquitetura. $O$ trabalho foi iniciado no segundo semestre de 2019, no início de 2021 foram entregues os títulos de posse do primeiro assentamento, e a previsão é de que os demais assentamentos sejam regularizados entre 2021-2022.

Cabe ainda destacar a atuação das mulheres para pautar a agenda pública. Nisso reside a importância de identificar as problemáticas locais com as pesquisas, saber analisa-las e compreendê-las, e direcionar as ações para que o poder público as inclua em suas políticas. Por exemplo, a questão da insegurança da terra foi identificada na pesquisa quantitativa, foi discutida com as mulheres, foi relatada ao poder público, foi dimensionada no levantamento feito junto aos cartórios (quando houve a descoberta que os terrenos pleiteados para a regularização fundiária eram públicos) e depois, com base em todo o trabalho no município se alcançou a promulgação de uma lei e o lançamento de um programa de regularização fundiária.

Nesse sentido, para incidir nas políticas de maneira articulada e consistente é necessário construir uma atuação qualificada a fim de que haja não

7 Em setembro de 2020 foi protocolado ofício na Corregedoria Geral de Justiça de Pernambuco sobre a REURB-S em virtude da inércia da prefeitura e no mês seguinte as monitoras entregaram ofício no gabinete da prefeita solicitando resposta sobre o processo de regularização, que foi inicialmente solicitado em 2018. 
apenas a implementação das políticas já previstas, mas que se insira na agenda pública outras políticas, como é o caso da regularização fundiária, que até então não era alvo de interesse do poder local. Ou seja, nesse caso se alcançou alterar a agenda municipal para atender a prioridade do conjunto de mulheres na exigibilidade de seus direitos; o que, por sua vez, se constitui como um resultado concreto do processo de monitoramento. A relevância disso pode ser apreendida na fala de uma das mulheres:

Pra mim vai ser muito importante porque vai ser um passo pra minha liberdade, né? E mais um passo a mais para meu empoderamento, porque vai ser realmente minha, minha casa, minha propriedade, vai ser minha. (...) Isso vai ser bom pra mim, pra minha família, pra o meu lar. É muito importante você poder dizer que é seu. Coisa que a gente aqui nem sabia nem passava na cabeça da gente que a gente morava numa casa há mais de 10 anos e que o terreno não era nosso. Aí agora a gente pode dizer que é nosso (Moradora de um dos assentamentos).

\section{Considerações finais}

O conjunto das ações desenvolvidas no processo de monitoramento das políticas nos municípios de Bonito e Caruaru demonstra as potencialidades da integração e inter-relação dos eixos do modelo de empoderamento do Espaço Feminista, pautado na horizontalidade, na dialogicidade e na participação coletiva, especialmente considerando que o objetivo do monitoramento é o de responder as principais questões indicadas nas pesquisas, que refletem as necessidades das mulheres, para assim contribuir com uma melhora nas condições de vida em suas comunidades.

As atividades seguiram a metodologia já apresentada e discutida, mantendo a imbricação entre o processo de construção de conhecimento, o processo formativo, a construção de alianças e o processo de incidência, que inclui monitoramento e diálogo com o poder público. O que tem contribuído para promover a autonomia e o protagonismo das mulheres das comunidades envolvidas, ponderando que a atuação das mulheres na articulação com o poder público fornece as possibilidades de compreender o empoderamento como redistribuição do poder e de redimensionar sua própria experiência.

A escolha do monitoramento como meio para incidir nas políticas públicas de forma articulada e consistente aponta à necessidade do conhecimento coletivo de cada contexto e do exercício do controle social por parte das mulheres e de suas comunidades para que a exigibilidade de seus direitos se converta em prática cotidiana.

No final do período 2018-2020 foram apontados alguns resultados do processo de monitoramento, que se relacionam tanto aos encaminhamentos e soluções efetivas às questões identificadas em cada comunidade dos dois mu- 
nicípios, quanto aqueles que têm caráter intermediário, formativo, de articulação ou preparatório. Estes são importantes para verificar o alcance do trabalho e possibilitar rever e ajustar alguns aspectos do processo. A identificação desses resultados é feita com base em uma matriz que inclui os seguintes componentes: eixo, ação, situação, quantitativo de famílias e mulheres beneficiadas.

Dessa forma, se apresentam como pontos fortes desse processo a atuação qualificada dos grupos em cada território a partir dos planos de monitoramento construídos coletivamente, colaborando assim para o estabelecimento e fortalecimento de vínculos entre as mulheres que transitam entre $o$ rural e o urbano a partir da percepção de problemas comuns e da necessidade de atuação conjunta e solidária e também para a autonomia e o crescimento crítico-político das mulheres desde uma perspectiva feminista.

Por outro lado, considerando que estas mulheres compartilham uma realidade comum de desigualdade de gênero, mas diferem quanto as suas situações de vida, e nos graus e níveis de opressão, alguns desafios foram postos na realização do trabalho, entre os quais: os tempos diferenciados para a apreensão das ações necessárias; as distintas condições locais; a necessidade de um período mais longo entre o planejamento e a implementação das ações; e o fator político local que pode influenciar de forma positiva ou representar uma dificuldade a mais para ser superada. Por isso a necessidade de identificar e se adequar aos desafios que surgem diante do modelo proposto, exigem flexibilidade, criatividade e atuação integrada. Contudo, esses desafios são minimizados na medida em que o trabalho é construído coletivamente com o protagonismo das mulheres e com base em seus problemas e experiências.

Por fim, cabe assinalar o reconhecimento por parte das mulheres do trabalho que vem sendo desenvolvido com o monitoramento da implementação das políticas públicas, capaz de gerar mudanças nos níveis individual, comunitário e local. Assim, no âmbito de influência nas políticas públicas as mulheres estão se constituindo em redes e atuando politicamente para reivindicar suas demandas enquanto grupo, a exemplo da regularização fundiária que está em curso.

\section{Referências}

BARDIN, Laurence. Análise de conteúdo. Lisboa: Edições 70, 1977.

BATLIWALA, Srilatha. El significado del empoderamiento de las mujeres: nuevos conceptos desde la acción. En: LEÓN, Magdalen. Podery empoderamiento de las mujeres. Santa Fe de Bogotá:T/M Editores, 1997, p. 
$187-211$

BUTTO, Andrea; HORA, Karla; DANTAS, Isolda. Políticas para as mulheres rurais: uma história de 10 anos. Revista do Observatório Brasil da Igualdade de Gênero. Brasília, Secretaria de Política para as Mulheres, abril, p. 130-140, 2014.

CAROSIO, Alba. Perspectivas feministas para ampliar horizontes del pensamiento crítico latinoamericano. In: SAGOT, Montserrat (org.) Feminismos, pensamiento crítico y propuestas alternativas en América Latina. Ciudad Autónoma de Buenos Aires: CLACSO, 2017, p. 17-42.

CASTAÑEDA, Martha. Metodología de la investigación feminista. Ciudad de México: UNAM, 2008.

CHAVES, Patrícia; LACERDA, Natáli. Linha de Base: descrição das atividades realizadas e indicação da metodologia de trabalho. Recife: Espaço Feminista, 2017.

CHAVES, Patrícia; LACERDA, Natáli. Linha de Base: descrição das atividades realizadas e indicação da metodologia de trabalho. Recife: Espaço Feminista, 2018.

DEERE, Carmen; LEÓN, Magdalena. Diferenças de gênero em relação a bens: a propriedade fundiária na América Latina. Revista Sociologias. Porto Alegre, UFRGS, n. 10, p. 100-153, 2003.

DEERE, Carmen. Tierra y autonomía económica de la mujer rural: avances y desafíos para la investigación. In: COSTAS, Patricia (comp.). Tierra de mujeres: reflexiones sobre el acceso de las mujeres rurales a la tierra en América Latina. La Paz: Fundación Tierra and International Land Rights Coalition, p. 41-69, 2011.

FEMENIAS, Maria Luisa. Esbozo de un feminismo latinoamericano. Revista de Estudos Feministas. Florianópolis, v. 15, n.1, p. 11-25, 2007.

FREIRE, Paulo. Pedagogia da autonomia. Rio de Janeiro: Paz e Terra, 1997.

GHEDIN, Evandro; FRANCO, Maria Amélia. Questões de método na construção da pesquisa em educação. São Paulo: Cortez, 2008. 
GIL, Antonio Carlos. Métodos e técnicas de pesquisa social. São Paulo: Atlas, 1994.

HERRERA FLORES, Joaquín. La reinvención de los derechos humanos. Valencia: Atrapasueños, Colección Ensayando 1, 2008.

LACERDA, Natáli. Linha de Base: descrição das atividades realizadas e indicação da metodologia de trabalho. Recife: Espaço Feminista, 2019a.

LACERDA, Natáli. Relatório Analítico do Processo de Monitoramento: formação para a localização dos ODS e para a incidência política. Recife, Espaço Feminista, 2019b.

LACERDA, Natáli. Linha de Base: descrição das atividades realizadas e indicação da metodologia de trabalho. Recife: Espaço Feminista, 2020a.

LACERDA, Natáli. Relatório 2 anos de monitoramento: empoderamento, formação e incidência política. Recife: Espaço Feminista, 2020b.

LAGARDE, Marcela. Género y feminismo, desarrollo humano y democracia. Cuadernos Inacabados, 25. Madrid: Horas y Horas La Editorial, 1996.

LAGARDE, Marcela. Claves feministas para la autoestima de las mujeres. Cuadernos Inacabados, 39. Madrid: Horas y Horas La Editorial, 2000.

LAGARDE, Marcela. Los cautiverios de las mujeres: madresposas, putas, presas y locas. Ciudad de México: UNAM, 2005.

LUGONES, María. Hacia un feminismo descolonial. Trad. Gabriela Castellanos. La manzana de la discordia, Cali, v. 6, n. 2, p. 105-119, 2011.

MANZANO, Irene Rodríguez. Sobre el término género. En: CARBALLO DE LA RIVA, Marta. Género y desarrollo: el camino hacia la equidad. Madrid: Catarata, 2006, p.32-56.

MELO, Anamaria. Relatório de Atividade Formativa. Recife: Espaço Feminista, 2019a.

MELO, Anamaria. Relatório Analítico do Monitoramento. Recife: Espaço 
Feminista, 2019b.

MÉNDEZ, Irene López. Más allá del desarrollo: la estrategia del empoderamiento. En: CARBALLO DE LA RIVA, Marta. Género y desarrollo: el camino hacia la equidad. Madrid: Catarata, 2006, p. 87-110.

ONU. Transformando Nosso Mundo: A Agenda 2030 para o Desenvolvimento Sustentável. 2015. Traduzido do inglês pelo Centro de Informações das Nações Unidas para o Brasil. 2016. Disponível em: http:// sustainabledevelopment.un.org. Acesso em: 20 nov. 2017.

PNUD. La Democracia en América Latina: hacía una democracia de ciudadanas y ciudadanos. Buenos Aires: Alfaguara, 2004.

SCOTT, Joan. Gênero: uma categoria útil de análise histórica. Educação e Realidade, Porto Alegre (UFRGS), v. 16, n. 2, p. 5-22, jul/dez. 1990.

SILVA, Carmen (org.). Experiências em pedagogia feminista. Recife: SOS Corpo, 2010.

TORRES, Alfonso. A Educação Popular como prática política e pedagógica emancipadora. In: STRECK, Danilo; ESTEBAN, Maria Teresa (org.). Educação Popular: lugar de construção social coletiva. Rio de Janeiro: Vozes, 2013, p. 15-32.

Recebido em: 15 de dezembro de 2020.

Aprovado em: 14 de maio de 2021. 